\title{
Analytic Methods for Quality Control of Scientific Publications Part VI: Presentation in Research Gate, Journal Indexing, and Recognition
}

\author{
Ilia Brondz \\ Drug Control and Drug Discovery Institute (NDCDDI), Ski, Norway \\ Email: ilia.brondz@gmail.com
}

How to cite this paper: Brondz, I. (2019) Analytic Methods for Quality Control of Scientific Publications Part VI: Presentation in Research Gate, Journal Indexing, and Recognition. International Journal of Analytical Mass Spectrometry and Chromatography, 7, 37-44.

https://doi.org/10.4236/ijamsc.2019.74005

Received: November 30, 2019

Accepted: December 28, 2019

Published: December 31, 2019

Copyright $\odot 2019$ by author(s) and Scientific Research Publishing Inc. This work is licensed under the Creative Commons Attribution-NonCommercial International License (CC BY-NC 4.0). http://creativecommons.org/licenses/by-nc/4.0/

\begin{abstract}
In the world of science, recognition of scientific performance is strongly correlated with publication visibility and interest generated among other researchers, which is evident by downloads and citations. A published paper's number of downloads and citations are the best indices of its importance and are useful measures of the researchers' performance. However, the published paper should be valuated and indexed independently, and the prestige of the journal in which it is published should not influence the value of the paper itself. By participating in and presenting at congresses and international meetings, scientists strongly increase the visibility of their results and recognition of their research; this also promotes their publications. Status in Research Gate (RG), the so-called RG Score, the Percentile, and the $h$-index give researchers feedback about their performance, or their place and prestige within the scientific community. RG has become an excellent tool for disseminating scientific results and connecting researchers worldwide. RG also allows researchers to present achievements other than publications (e.g., membership in recognized associations such as the American Chemist Society, a biography in Marquis Who's Who in the World, awards received, and/or ongoing projects). This paper discusses questions regarding how the RG Score, Percentile, and $h$-index are calculated, whether these methods are correct, and alternative criteria. RG also lists papers with falsified results and the journals that publish them. Thus, it may be appropriate to reduce the indices for such journals, authors, and the institutions with which these authors are affiliated.
\end{abstract}

\section{Keywords}

Education Institution, Quality of Publication, Recognition in Scientific 
Community, Criteria of Judgment for Publication, Indexing,

Falsified Research

\section{Introduction}

Publications in high-indexed journals are rewarded by RG with a higher ranking and are more highly valued within academic institutions such as universities and research institutes. However, the methods by which a journal's index is calculated and whether it is appropriate are open questions. Other questions include whether the journal's index should include falsifications and forgeries, whether these should be retained after the forgeries have been disclosed (i.e., when the forged papers are not retracted by the journal), and what influence this should have on the journal's index. These issues concern all sciences, especially those for which accurate reporting of scientific results has a crucial impact on development of new knowledge and replication, including support for or renunciation of recent discoveries. This process is important in 1) chemistry, including analytical chemistry, 2) other branches important to the medical sciences, such as toxicology (especially occupational toxicology), 3) experimental physics, and many others. Notable examples of inaccurate reporting practices within medical toxicology have included the side effects of thalidomide [1] and the high prevalence of contamination of primaquine with quinocide [2] [3] [4]. These publications [2] [3] [4] led to the prevention of crippling of thousands of patients due to contaminated primaquine. Should the journals which published forgeries suffer reduced index values, especially in cases where they hid and retained such forgeries intentionally? Should those journals which have denied publication of the truth [2] [3] [4] suffer reduction of their index values? Should those journals which have published the truth [2] [3] [4] and divulged the fakes be rewarded with higher index values?

With the disintegration of the USSR in the 1990s, hundreds of newly established colleges and universities began to appear in its former territories. The same process occurred following WWII, after disintegration of the colonial system in developing nations. Many of those newly established centers of education lacked sufficient scientific ethics and traditions of scientific quality and morals [5]. We have an international scale to measure the performance of scientific institutions and universities. The indexing of publications must therefore be normalized in accordance with the source of their production (i.e., the educational or research center) but not in accordance with where it is presented (i.e., the journal of publication). Indexing should be based on the same criteria that have been accepted for the production of industrial goods within the international marketplace. Goods produced by well-known manufacturers cost more than replica goods, goods produced without a license, and goods from less qualified locations. The RG Score, Percentile, and $h$-index of publications submitted from 
one of the top 100 institutions within the international scale should be multiplied by 1.0; those submitted from secondary institutions (i.e., the next 100) should be multiplied by 0.75 ; those submitted from tertiary institutions should be multiplied by 0.5 , etc. The rationale for normalizing publication values in this way is that research carried out at the lower-tiered institutions follows a less critical approach to the scientific process (see examples below).

One example of this is publication of the "super discovery" of thin-layer chromatographic enantiomeric separations without using selectors in the mobile or stationary phases and without transforming the substances to diastereomers [6]. Critiques of this amazing publication in [6] were published and presented in [7]. Another example is the inclination of scientists working at institutions that have a lower international scale (i.e., have a worse reputation) to accept industry bribes, in the form of grants, for presenting analyses indicating that medications are of better quality than the research actually showed [8]. The deep scientific quagmire of the researchers, journal reviewers, and Editor-in-Chief who published the results [8] of capillary electrophoresis were all involved in obvious fraud. As if this was not enough, a variation of the same fraudulent text was published again in [9]. The fraud was exposed in [10], and a critique of these two publications ([8] and [9]) was also presented in [11]. Involvement of the pharmaceutical industry in false publications about drug quality via bribery of scientists with low ethics and who work at lower-tiered institutions has also been described [11]-[19].

The Nobel Prize is an ultimate recognition of scientific and other human performance, yet even this distinction is vulnerable to fraud, especially when awarded for political reasons. If respectable researchers publish in respectable journals, this does not guarantee that the truth is presented in these "scientific research" texts (some of which are more accurately described as pseudoscientific research), as shown in the case of Linda Buck, who shared the 2004 Nobel Prize in Physiology or Medicine. She was exposed for fraud in two papers, published in 2005 and 2006, which formed the basis for granting her the Nobel Prize. She later retracted both publications. Both retractions-from the Proceedings of the $\mathrm{Na}$ tional Academy of Sciences (PNAS) and Science [20]-nullified both her research and the basis for her decoration with the Nobel Prize. Thus, even publication in prestigious journals such as PNAS and Science and decoration with the Nobel Prize is insufficient to ensure the quality and truth of published data. There have been especially negative effects of such politically or gender motivated decisions by members of committees granting the Nobel Prize for Science (in Sweden) and for Social Science (in Norway). Albert Einstein has never been decorated with the Nobel Prize in Physics for his Theory of Relativity. He received the Nobel Prize for his "services to theoretical physics, and especially for his discovery of the law of the photoelectric effect." This occurred due to a misunderstanding of relativity by many scientists, and misunderstanding of the paragraph in the constitution of the Nobel Prize stating that achievements must 
be supported by proof with time. However, this did not prevent Linda Buck from receiving the Nobel Prize (despite the fact that only a short time had passed since her publications and no support for her data was available). The same has occurred regarding politicians whose future achievements were predicted, yet unsupported by proof at the time of the award. US President Obama received the Nobel Prize for his future efforts to establish peace around the globe. He was rewarded with the Nobel Prize in advance, before he did anything and despite despicable military and other acts against countries around the globe that occurred later during his time in office. The Nobel Prize committee apparently could not wait several years for the proof of time, in accordance with its constitution, to award the Nobel Prize to Linda Buck, Barack Obama, or Al Gore.

It is shameful when, despite well-documented cases of fraudulent publication, the Editor-in-Chief of a journal conceals the fraud and denies strong arguments demanding that this fraud be withdrawn; such acts, reflecting lack of trustworthiness of the publisher, deserve a reduced index for the journal. Editor-in-Chief Bezhan Chankvetadze of the Journal of Pharmaceutical and Biomedical Analysis, published by Elsevier, concealed a fraudulent publication (perhaps an unsurprisingly corrupt action, since Mr. Chankvetadze is a compatriot of former Soviet dictator Josef Stalin, in a society where fraud and corruption were common). The fraudulent, concealed publication [21] and documentation of the fraud have been published in [3] [4] [22] [23].

No argument or publication in the international scientific literature as in [3] [4] [22] [23] can help in the struggle to restore truth or lead to results, because the representatives of this deep scientific and publishing house entanglement are supported by a corrupt industry and collusion. For example, one paper [21], a stolen text [2] which was later published. [2] was submitted to the Asian Journal of Chemistry, where it was reviewed by Dr. Surendra Prasad from Fiji and Editor-in-Chief Mr. Agrewal, both of whom were in possession of the submitted and unpublished original manuscript [2], which had been disseminated or possibly even sold. The author of the fraudulent paper [21], Mr. Dongre, the reviewer, and the Editor-in-Chief were guarded from disclosure of their activities by their society of corrupt colleagues in a broad, deep publication industry morass. However, fresh forces exist beyond this deep scientific quagmire. Disclosure of the facts about this fraud to the rector of Mumbai University resulted in deletion of the fraudulent paper [21] from Mr. Dongre's list of publications, and he was later fired from his position at Mumbai University. The facts surrounding this fraud and misuse of trust by the reviewer and Editor-in-Chief of the Asian Journal of Chemistry were disclosed in a letter to the Department of Higher Education, Central Universities, Ministry of Human Resource Development in India, resulting in the closure of the Asian Journal of Chemistry, eliminating this dirty business of selling the texts of submitted manuscripts. Another example of shameful fraud is the publication of two papers [8], [9] through a collaboration between the Editor-in-Chief of the journal Current Chromatography, Mr. Nes- 
terenko, who then retained one of the authors of these papers, Mr. Aboul-Enein, as Associate Editor for the journal. More information and a critique of this event have been published in [10] [11].

\section{Indexing}

Indexing of journals should not be based on duration of publication of journal, since even one year can be enough if the articles in the journal are of sufficiently high professional quality and interest. Rather, high professional interest in the published papers should be the main criterion for journal indexing. In addition, the index should only reflect interest in the papers in the journal.

The existing practice of rewarding scientists with university permission to use grant funds to publish in a journal of distinction, or in a journal published by a publisher of distinction, is wrong. It is wrong because the journals or publishers themselves are often connected by interests with universities, and vice versa, and thus they support one another with both high-quality and fraudulent publications. This deep scientific mire was established centuries ago.

Scientists should have freedom to choose their publishers and journals without university pressure. The rationale for abolishing existing practices is the partiality of some scientists who serve on the editorial boards of university-recommended journals. These scientists provide their universities with lists of journals with which they are affiliated, and in which scientists can publish papers using grant subsidies. In this way, universities are subsidizing these journals and the journals, in turn, are promoting the university's scientists. This practice is corrupt and unacceptable. A journal's prestige and indexing should be based on the value of and professional interest in the articles it contains-the prestige of a paper should not be based on the prestige and indexing of the journal in which it is published. It is simple to measure the usefulness of and professional interest in a paper based on its number of views, downloads, and citations. These are the only correct judgment values. For example, one paper [24] was viewed 55,596 times, downloaded 54,800 times, and cited by Google Scholar 9 times and by CrossRef 3 times; another paper [25] was viewed 35,234 times, downloaded 17,326 times, and cited by Google Scholar 139 times and by CrossRef 80 times; a third paper [26] was viewed 25,108 times, downloaded 22,066 times, and cited by Google Scholar 3 times and by CrossRef twice; a fourth paper [27] was viewed 19,580 times, downloaded 7,959 times, and cited by Google Scholar 59 times and by CrossRef 42 times. Professional interest in these papers can be evaluated based on the total number of views and downloads using the index of views and downloads (V/D index) which, for these papers, are 1.0145 [24], 2.0336 [25], 1.1379 [26], and 2.4601 [27]. The paper with the V/D index closest to 1 has shown the highest professional interest.

Why Are Total V and D, Indexing by V/D, and Citation Important?

In the pre-Internet days, scientists used printed catalogs such as SciFinder Scho- 
lar to access short descriptions of published papers and their citations. These accessible guides allowed scientists to decide whether a paper was useful and interesting to them and whether they should read similar publications (i.e., those cited in the paper). If so, such services allowed scientists to send a postcard of request to the author; for the author, the number of postcards they received was a success indicator. In the Internet era, open access journals have especially good statistics about the numbers of views, downloads, and citations for each published paper. The drawback of RG is its lack of overview of the number of views and downloads because it only counts those that were done through RG. The same drawback is true for Google Scholar and others.

As such, popularity and availability influence the indexing results. If a single index is to provide a real measure of the success of a paper or a scientist, the total numbers of views, downloads, and citations from all sources should be included.

\section{Research Gate}

RG is a unique tool that allows scientists to judge their own and others' performance and quality. However, the practice of ranking journals and publications with the RG Score, Percentile, and $h$-index should be more objective and independent of pre-existing indices. Along with RG information, every connected researcher can post their projects under development, questions, and answers, allowing them to communicate with other scientists and to provide and discover papers free of charge. In this way, RG may obtain a leading role as an institution for development of scientific reflection, connections, and development.

\section{Conclusions}

Journal indexing should be dynamic and revaluated annually. Indices must be based on both interest in the papers they publish and the fraudulent papers they publish, especially those renounced publicly as fraud rather than being retracted by the Editor-in-Chief. Neglecting to retract a fraudulent paper forthwith should be punished by zeroing that journal's index.

A list of researchers, reviewers, editors, and especially Editors-in-Chief who have participated in publishing fraudulent papers should be published by RG and elsewhere (for example, the paper [21], which publicly exposed two fraudulent publications in [22] [23]). This is the best method to drain the deep scientific mire of fraud, corrupt editors, and corrupt journals.

RG should be further developed as a complete system (i.e., an institution) with independent scales for judging scientific presentations and annual reports of the best publications, which will allow scientists a broad arena for discussions about improving the system of recognition within RG, such as the RG Score, Percentile, and $h$-index, as well as a venue for disclosing fraud. RG should allow the opportunity to disclose fraud in scientific publications, academic societies, the scientific community, and educational and research institutions. Direct use of a journal's index by RG for calculating the RG Score, Percentile, and $h$-index, by 
which scientists are recognized in RG, should be changed to the total V and $D$, the $\mathrm{V} / \mathrm{D}$, and the number of citations.

\section{Conflicts of Interest}

The author declares no conflicts of interest regarding the publication of this paper.

\section{References}

[1] http://broughttolife.sciencemuseum.org.uk/broughttolife/themes/controversies/thal idomide

[2] Brondz, I., Klein, U., Ekeberg, D., Mantzilas, D., Hvattum, E., Schultz, H. and Mikhailitsyn, F.S. (2005) Nature of the Main Contaminant in the Anti-Malaria Drug Primaquine Di-Phosphate: GC-MS Analysis. Asian Journal of Chemistry, 17, 16781688.

[3] Brondz, I. (2012) Analytical Methods in Quality Control of Scientific Publications. American Journal of Analytical Chemistry, 3, 443-447. https://doi.org/10.4236/ajac.2012.36058

[4] Brondz, I. (2014) Analytical Methods in Quality Control of Scientific Publications Part III: Publishers' Ethics and Editors' Complicity. International Journal of Analytical Mass Spectrometry and Chromatography, 2, 77-102. https://doi.org/10.4236/ijamsc.2014.23008

[5] Brondz, I. (2015) The Journal Voice of the Publisher. Voice of the Publisher, 1, 1-7. https://doi.org/10.4236/vp.2015.11001

[6] Gong, S.X., Lei, Z.Y. and Wu, W. (2005) Study on the Test for Related Substances of Primaquine Phosphate by TLC and Its Enantiomers. China Pharmaceuticals, 14, 36-37. (In Chinese)

[7] Brondz, I. (2013) Analytical Methods in Quality Control of Scientific Publications Part II the Authors', Reviewers', Editors' Responsibility and the Publishers' Authority. International Journal of Analytical Mass Spectrometry and Chromatography, 1, 81-89. https://doi.org/10.4236/ijamsc.2013.12010

[8] Elbashir, A.A., Saad, B., Ali, A.S.M., Saleha, M.I. and Aboul-Enein, H.Y. (2008) Development of a Capillary Electrophoresis Method for the Enantioselective Estimation of Primaquine in Pharmaceutical Formulations. Journal of AOAC International, 91, 536-541.

[9] Elbashir, A.A., Saad, B., Ali, A.S.M., Saleha, M.I. and Aboul-Enein, H.Y. (2009) Determination of Quinocide as Impurity in Primaquine Tablets by Capillary Zone Electrophoresis. Biomedical Chromatography, 23, 464-471.

https://doi.org/10.1002/bmc.1137

[10] Brondz, I. (2015) Analytical Methods in the Quality Control of Scientific Publications Part V: The Fraud of Pseudoscientists Based on False Measurements and Method Development. International Journal of Analytical Mass Spectrometry and Chromatography, 3, 25-31. https://doi.org/10.4236/ijamsc.2015.32003

[11] Brondz, I. (2014) Analytical Methods in Quality Control of Scientific Publications Part IV: Fraud Ordered by the Pharmaceutical Industry. International Journal of Analytical Mass Spectrometry and Chromatography, 2, 103-112. https://doi.org/10.4236/ijamsc.2014.24009

[12] http://www.rsc.org/chemistryworld/2014/09/gsk-fined-300million-china-corruption 
[13] http://www.nytimes.com/2014/09/20/business/international/gsk-china-fines.html

[14] http://www.the-scientist.com/?articles.view/articleNo/27383/title/Elsevier-published -6-fake-journals

[15] http://www.the-scientist.com/?articles.view/articleNo/27376/title/Merck-publishedfake-journal

[16] Jia, H. (2014) GSK Fined $£ 300$ Million for China Corruption. http://www.rsc.org/chemistryworld/2014/09/gsk-fined-300million-china-corruption

[17] Bradsher, K. and Buckleysept, C. (2014) China Fines GlaxoSmithKline Nearly $\$ 500$ Million in Bribery Case. The New York Times, 19 September 2014. http://www.nytimes.com/2014/09/20/business/international/gsk-china-fines.html? $\mathrm{r}=0$

[18] Grant, B. (2009) Elsevier Published 6 Fake Journals. The Scientist, 7 May 2009. http://www.the-scientist.com/?articles.view/articleNo/27383/title/Elsevier-published -6-fake-journals

[19] Grant, B. (2009) Merck Published Fake Journal. The Scientist, 30 April 2009. http://www.the-scientist.com/?articles.view/articleNo/27376/title/Merck-publishedfake-journal

[20] http://retractionwatch.com/2010/09/23/nobelist-linda-buck-retracts-two-studies-on -olfactory-networks-and-the-news-is-embargoed

[21] Dongre, V.G., Karmuse, P.P., Nimbalkar, M.M., Singh, D. and Kumar, A. (2005) Applications of GC-EI-MS for the Identification and Investigation of Positional Isomer in Primaquine, an Antimalarial Drug. Journal of Pharmaceutical and Biomedical Analysis, 39, 111-116. https://doi.org/10.1016/j.jpba.2005.03.019

[22] Quintin, T.J. (2010) Chromatography: Types, Techniques and Methods. Chapter 6, Nova Science Publishers, Inc., New York, 281-322.

[23] Brondz, I. (2011) Historical Overview of Chromatography and Related Techniques in Analysis of Antimalarial Drug Primaquine. Nova Science Publishers, Inc., New York.

[24] Udom, I., Myers, P., Ram, M., Hepp, A., Archibong, E., Stefanakos, E. and Goswami, D. (2014) Optimization of Photocatalytic Degradation of Phenol Using Simple Photocatalytic Reactor. American Journal of Analytical Chemistry, 5, 743-750. https://doi.org/10.4236/ajac.2014.511083

[25] Sassolas, A., Prieto-Simón, B. and Marty, J. (2012) Biosensors for Pesticide Detection: New Trends. American Journal of Analytical Chemistry, 3, 210-232. https://doi.org/10.4236/ajac.2012.33030

[26] Brondz, I. (2013) Structure Elucidation of a New Toxin from the Mushroom Cortinarius rubellus Using Gas Chromatography-Mass Spectrometry (GC-MS). International Journal of Analytical Mass Spectrometry and Chromatography, 1, 109-118. https://doi.org/10.4236/ijamsc.2013.12014

[27] Roy, A., Tripathy, D., Chatterjee, A. and Dasgupta, S. (2010) A Spectroscopic Study of the Interaction of the Antioxidant Naringin with Bovine Serum Albumin. Journal of Biophysical Chemistry, 1, 141-152. https://doi.org/10.4236/jbpc.2010.13017 